\title{
O PAPEL DO CABO ELEITORAL NAS DISPUTAS PELO PODER LOCAL: SABER PROFISSIONAL, CAMPANHA POLÍTICA E FACÇÕES EM ARAPONGAS/SE $(2014-2015)^{12}$
}

\author{
Pâmella Synthia Santana Santos ${ }^{3}$
}

\begin{abstract}
RESUMO
O objetivo deste artigo é demonstrar a relação do ofício de cabo eleitoral e grupos políticos com o propósito de contribuir para a manutenção e ampliação do poder local, além de demonstrar que o cabo eleitoral é um ator chave no que concerne a disputa do jogo político. Através da observação participante, foram acompanhados nove cabos eleitorais no município de Arapongas no interior de Sergipe, antes e durante a campanha eleitoral de 2014, que trabalhavam para candidatos que pleiteavam a todos os cargos políticos, tendo em vista a necessidade de entendimento acerca de suas práticas desse seu saber político. Também foram feiras entrevistas semiestruturadas com esses cabos eleitorais com o propósito de compreender a visão de mundo desses atores sobre o seu espaço de atuação dentro e fora dos grupos políticos. Isso resultou em uma ampla visão sobre as diversas relações pessoais e políticas, que estão presentes no dia a dia desses grupos para poderem então preservar ou aumentar o seu poder político, visto a fluidez dos vínculos políticos que podem acabar atravessando os muros desses grupos.
\end{abstract}

Palavras-chave: cabo eleitoral; grupos políticos; poder local.

\begin{abstract}
The objective of this article is to demonstrate the relationship of the canvasser and political groups with the purpose of contributing to the maintenance and expansion of the local power, besides demonstrating that the canvasser is a crucial actor in what concerns the political dispute. Nine canvassers were accompanied through a participant observation, before and during the 2014 election campaign in the city of Arapongas in the countryside of Sergipe, who worked for candidates claiming all political offices, in view of the need to understand their practices of political knowledge, as well as semi-estructured interviews with these canvassers in order to comprehend the world's views of these actors about their acting area inside and outside of the political groups. This has resulted in a broad vision about different personal and political relations, that are present day to day at these groups, so they can preserve or increase their political power, also due to the fluidity of political links that can trespass the walls of those groups.
\end{abstract}

Keywords: canvasser; political groups; local power.

\section{RESUMEN}

El objetivo de este artículo es demostrar la relación del oficio de cabo electoral y grupos políticos con el propósito de contribuir al mantenimiento y ampliación del poder local, además de demostrar que el cabo electoral es un actor clave en lo que concierne a la disputa del juego político. A través de la observación participante, se acompañaron nueve cables electorales en el municipio de Arapongas en el interior de Sergipe antes y durante la campaña electoral de 2014, que trabajaban para candidatos que pleiteaban a todos los cargos políticos teniendo en vista la necesidad de entendimiento acerca de sus prácticas de su saber político, como también entrevistas semiestructuradas con esos cables electorales con el propósito de comprender la visión de mundo de esos actores sobre su espacio de actuación dentro y fuera de los grupos políticos. Eso resultó en una amplia visión sobre las diversas relaciones personales y políticas, que están presentes en el día a día de esos grupos para poder entonces preservar o aumentar su poder político, visto la fluidez de los vínculos políticos que pueden acabar atravesando los muros de esos grupos.

Palabras clave: cabo electoral; grupos políticos; poder local.

\footnotetext{
${ }^{1}$ Enviado: $31 / 03 / 2017$

Aceito: $22 / 06 / 2017$

2 DOI: $10.5380 /$ recp.v8i1.51564

${ }^{3}$ Doutoranda no Programa de Pós-Graduação em Sociologia pela Universidade Federal de Sergipe; Mestra em Sociologia (PPGS/UFS); bacharela em Ciências Sociais pela UFS; graduanda em Ciências Sociais - Licenciatura pela UFS.
} 
Este artigo busca debater sobre o ofício de cabo eleitoral e sua atribuição no que concerne às disputas pelo poder local, seja no período eleitoral ou nos momentos que antecedem esse período, tendo em vista que a principal ocasião na qual esse ator tem mais visibilidade é na campanha eleitoral. Todavia, vai ser mostrada também a importância de sua representação nesses momentos do antes e depois da campanha. É perceptível que o saber que esses atores mobilizam proporcionam a possibilidade de se manterem no jogo político, considerando também que as alianças políticas podem se desfazer a qualquer momento e as que viriam a substituir podem implicar em algumas desavenças, como formação de alianças com candidatos que acabam jogando nos dois lados.

Para poder exemplificar esse debate, o universo empírico conta com nove cabos eleitorais que estão inseridos em dois grupos políticos, cujos nomes são Matamatá e Chochara, que existem há mais de 40 anos no município de Arapongas, localizado na região centro-sul de Sergipe. Com isso, a observação participante antes, durante e depois da campanha eleitoral foi feita com o propósito de compreender como se dá o seu cotidiano profissional - mais especificamente no período que compreende de maio a novembro de 2014 , além dos encontros feitos posteriormente a esse período, focando na interação após o período eleitoral -, lidando com diversas situações, que acabam perpassando a imagem do cabo eleitoral. Além disso, foram feitas entrevistas semiestruturadas - feitas entre outubro e dezembro de 2015, além das conversas que surgiam durante as observações - objetivando identificar o perfil desse profissional, não apenas enquanto profissional, mas como um ator que está sujeito à socialização entre os espaços de que faz parte e na construção do ofício de cabo eleitoral. Devese deixar claro que esses cabos eleitorais estavam atuando na campanha de 2014, trabalhando para candidatos de todos os cargos que estavam sendo pleiteados, além de que esses atores já se encontravam dentro da política profissional por estarem exercendo no momento desta pesquisa o mandato de vereador no mesmo município. Metade desses cabos eleitorais aqui colocados já exerceram outros mandatos de vereador enquanto que a outra metade exercia o seu primeiro mandato, apesar de já ter tido uma vivência na política, através de suas participações dentro de determinado grupo político.

A escolha do município se deu devido a sua influência na política estadual como também por se tratar de um local com uma disputa política entre dois grupos (famílias adversárias e agregados) que surgiram após o fim do coronelismo e se consolidaram na década de 1970. Para isso, volta-se mais ainda para o período da Primeira República, onde em Sergipe os grupos Pebas e Cabaús tinham seus representantes em cada município. Com o surgimento de novos partidos durante a República, como o Partido Democrático Sergipano e o Partido 
SANTOS, P. S. S. O papel do cabo eleitoral nas disputas pelo poder local: saber profissional, campanha política e facções em Arapongas/SE (2014-2015)

Republicano Federal Sergipano, esse último acabou se dividindo em dois: os velhos políticos, muitos deles senhores de engenho, foram denominados, juntamente com os seus adeptos, de "Cabaús" - nome do mel de engenho -, enquanto os adversários tiveram o nome de "Pebas" ou tatus. Essas denominações apareceram em 1894, quando o grupo composto principalmente por militares e republicanos históricos, inconformado pela vitória dos políticos adesistas nas eleições para a Assembleia Legislativa, resolveu tomar o governo através de golpe (OLIVA, 1991).

Isso ocorreu durante o mandato do primeiro presidente eleito do estado, o General José Calazans. Os republicanos, ignorando os resultados eleitorais proclamados pelo governo, ocuparam o palácio e consideraram eleitos apenas os candidatos do seu partido. O presidente Calazans e os deputados que o seu governo havia considerado eleitos saíram de Aracaju para Rosário do Catete, procurando de lá administrar o estado. Mas os republicanos instituíram novo governo, dirigido por João Vieira Leite, e um Legislativo formado apenas por deputados republicanos. Essa situação, que se transformou num caso de repercussão nacional, segundo Oliva (1991), fez a política sergipana dividir-se em Pebas e Cabaús, mantendo-se os pebas no poder até 1898, quando o Monsenhor Olímpio Campos, que se tornara chefe dos Cabaús, conseguiu aliar-se com uma parte dos pebas, criando o Partido Constitucional Sergipano (PCS). Os pebas que não participaram desse acordo com os Cabaús, liderados pelo Coronel Valadão, recriaram o Partido Republicano Federal.

Em Arapongas, o grupo Pebas, tendo à frente as famílias Brito e Saraiva, tinha como principal chefe político Antônio Brito, uma das maiores figuras da política do município, estando entre os intelectuais do pensamento social brasileiro sobre a mestiçagem; e os Cabaús, tendo um grupo de coronéis que confrontavam fortemente os Pebas durante a República Velha. Blondel (1957) afirma que em cada estado tinha o seu partido, o Partido Republicano. Desta forma, existiam vários partidos na Câmara Federal, embora fossem partidos distintos pela origem geográfica, nunca pelas tendências políticas (DANTAS, 2004). Esse fato perdura até os dias de hoje, com o modelo político de grupos, em Arapongas; assim como os Pebas e Cabaús, a política faccional teve continuidade com duas famílias que se opõem até os dias atuais Chocara e Matamatá - e norteiam a política municipal, como também têm destaques em nível federal. Com o fim do coronelismo, os grupos precisaram se adaptar a nova realidade, levando assim ao desaparecimento do grupo Pebas e ao dissolvimento do grupo Cabaús, onde aconteceu um desentendimento com duas lideranças. Esse fato proporcionou o apadrinhamento do líder do Cochara, e posteriormente dividiu o padrinho com o líder do Matamatá. 
A nomenclatura surgiu através de uma novela da Rede Globo que estava sendo transmitida no mesmo período em que acontecia uma eleição municipal no final da década de 1970, onde também havia dois grupos e que de certa maneira acabava se encaixando com a situação política de Arapongas. Os nomes conseguiram permanecer, além de ambas as famílias conseguirem se consolidar politicamente (além de seus agregados e apadrinhados), fazendo com que chegassem ao nível federal (maior cargo atual).

Pode aparentar um pouco confuso, mas é clara a participação de políticos locais na campanha de candidatos a cargos maiores, principalmente por aqueles candidatos que não tem uma boa recepção no município, além de os próprios cabos eleitorais utilizarem esse momento de visita e campanha para anteceder a sua própria campanha, visto que na política é necessário estar em evidência, além de ter aliados fortes, para demonstrar a sua força política. Com isso, os próprios cabos eleitorais têm os que são chamados de "cabos eleitorais secundários" que viriam ser aqueles que não "vivem" da política e que utilizam esse momento para conseguir algo futuro. Para um candidato ao Senado, por exemplo, convidar um sujeito para te apoiar na campanha, este último deve demonstrar que "tem gente que trabalha", que "é conhecido", logo, precisa ter seus próprios aliados, tanto que para se estar nesse meio, é necessário um network.

Como estratégia metodológica, foi optado por utilizar nomes falsos, sejam eles referentes aos atores, município, grupos, etc. com o intuito de resguardar aqueles que contribuíram para a pesquisa, vide que elementos dessa poderiam comprometer a imagem como também a segurança. No próprio município seria fácil descobrir a quem se refere cada informação, por causa da própria configuração dos grupos e das características que aparecem sobre os atores. Fora isso, o que dá mais riqueza ao trabalho não são os nomes em si, mas o que eles representam, apesar de que a história por trás desses grupos políticos do município em questão seja bastante rica.

A quantidade de cabos eleitorais estudados não foi proposital, mas sim o que o próprio campo possibilitou. Mais especificamente, a receptividade de uma pessoa de não confiança, de seu círculo, estar sempre presente no seu dia a dia, estando em reuniões comprometedoras não foi fácil de ser conquistada, por mais que houvesse um contato que possibilitasse a minha entrada no meio. Foram esses nove cabos eleitorais que se dispuseram a abrir caminho e permitir a uma outsider registrar momentos dos mais variados, desde uma visita a um eleitor até uma reunião com os coordenadores de campanha para estabelecer valores sobre os seus trabalhos. Quanto ao perfil desses cabos eleitorais há algumas variações: todos do sexo

\footnotetext{
${ }^{4}$ Situações que os próprios cabos eleitorais falaram em entrevista.
} 
SANTOS, P. S. S. O papel do cabo eleitoral nas disputas pelo poder local: saber profissional, campanha política e facções em Arapongas/SE (2014-2015)

masculino, exerciam o mandato de vereador no município de Arapongas, cinco deles já eram veteranos na política eletiva e quatro estavam no seu primeiro mandato; dos nove, dois tinham somente o ensino fundamental completo, dois tinham o ensino médio completo, enquanto cinco tinham o ensino superior completo (cursos de Gestão Pública, História, Economia, Administração, sendo este último o curso de dois cabos) e dentro desse grupo, um deles tem o título de mestre em Economia.

Quanto a esse estudo, com o auxílio do diário de campo, ficou perceptível como a esfera política é um universo complexo de se analisar, ainda que não tenha sido tão difícil inserir-se nele. A partir de contatos já pré-estabelecidos no município, o acesso aos cabos eleitorais e o acompanhamento não foi um problema, de igual feita deu-se o acesso a informações que são "privilegiadas" às pessoas do meio político. Não houve grande dificuldade para conversar com os "cabos eleitorais" porque eles sempre se mostravam dispostos a conversar e falar, ainda que informalmente, sobre as suas carreiras políticas.

O acompanhamento foi feito não só durante todo o período eleitoral, mas também antes dele, no momento em que as alianças e acordos estavam sendo feitos e/ou sendo analisados. Essa parte é importante porque justifica o motivo de ter sido escolhido o cabo eleitoral que é vereador, que faz carreira política e que tem acesso a outros políticos de maior prestígio. É esse o cabo eleitoral que sempre está em contato com os candidatos e que prepara toda a campanha em sua cidade, bem como, quem aciona os "cabos eleitorais secundários". Reuniões nos gabinetes dos candidatos, em suas próprias casas, ou até então nas casas dos "cabos eleitorais", inauguração de comitês, comícios, passeatas, carreatas, e demais eventos políticos contribuíram para a análise do objeto na atuação do seu papel de "cabo eleitoral". Além desses eventos, inserem-se também as sessões na Câmara Municipal de Vereadores, nas quais eles usavam a legitimidade do seu poder político para também fazer campanha eleitoral.

\section{SABER PROFISSIONAL EM JOGO: COMO OS GRUPOS POLÍTICOS INFLUENCIAM NA ATUAÇÃO DO CABO ELEITORAL}

Neste trabalho, por mais que se apresente na prática exemplos de patronagem ${ }^{5}$ ou clientelismo, não nos focaremos a esses conceitos, mas sim no que eles implicam para o

\footnotetext{
${ }^{5}$ Grynszpan (1990) coloca que o conceito de "patronagem" se refere a uma relação vertical com vínculo pessoal, a qual possibilita a acessibilidade a determinados recursos, bens e etc., que de outra maneira não seria possível. $\mathrm{O}$ autor ainda coloca o clientelismo em paralelo, mostrando que no Brasil a literatura tem seguido por esse viés para tratar da reflexão sobre as relações pessoais hierarquizadoras, e que por mais que Carvalho (1997) coloque que a curva do clientelismo tenha decaído com os anos, ela permanece, pois, acaba se adaptando ao contexto político-
} 
cotidiano da política no contexto analisado. Não se nega a importância analítica dos mesmos, com trabalhos clássicos vindos de grandes teóricos das Ciências Sociais como Grynszpan (1990) e Carvalho (1997). Todavia, penso que ao citar esses conceitos, poderíamos correr o risco de praticar um reducionismo a essas práticas e passar uma imagem de que essas ações são corruptas, erradas, ou algo do gênero; ao utilizar como base Queiróz (1976), de que a política em si começa no município e pensar as relações de parentela aliadas com os trabalhos já mencionados no corpo deste, penso que poderá haver uma compreensão mais fluida. Não nego também que exista a prática clientelística, mas introduzimos de forma mais geral dentro de uma perspectiva da questão da base eleitoral com Bezerra (1999) e Kuschnir (2000) e dos agrupamentos e facções pensados por Palmeira (1998), Palmeira e Barreira (2004), Palmeira e Heredia (2010), Camargo (2012), Landé (1977), e os já citados Carvalho (1997) e Grynszpan (1990).

As campanhas políticas não se resumem a uma disputa de cargos eletivos. Possuem, ao contrário, significados que lhes antecedem e transcendem os resultados eleitorais a depender de como é feito o trabalho pelos candidatos (KUSCHNIR, 2000). Além da definição de jogos de interesses, alianças e conflitos que se apresentam nesse momento, as campanhas podem ser percebidas através de um dos sentidos dos rituais políticos, que é a expressão de crenças e princípios que justificam e alimentam a própria existência da representação no Estado moderno.

Como as próprias ações políticas (ações próprias do tempo da política) supõem promessas recíprocas (a promessa do candidato e a promessa do eleitor de votar no candidato), elas se enquadram no modelo do favor/ajuda. Assim, mesmo quando não há compromissos preexistentes, as ações políticas são capazes de gerar compromissos. E boa parte da arte do político consistirá em conseguir adesões através de compromissos criados por sua própria ação na época da política (i.e., criados na própria campanha). No âmbito das campanhas políticas, a representação aparece como um dos elementos mais significativos, dotando os eventos de campanha de oportunidade, por excelência, de transferir direitos e ordenar legitimidades. As campanhas aparecem como uma espécie de tempo inaugural, que define quem irá falar em nome de quem e em nome de que conjunto de valores. Instalam, portanto, um espaço de discussão e construção de atores, discursos e imagens. Essa construção passa longe da espontaneidade, supondo-se que nesse processo conformam-se estratégias e modos variados de se fazer apresentar.

social. 
SANTOS, P. S. S. O papel do cabo eleitoral nas disputas pelo poder local: saber profissional, campanha política e facções em Arapongas/SE (2014-2015)

Se para o prefeito a adesão da oposição à sua base parlamentar garante-lhe mais apoio no Legislativo, o fato transforma-se em um problema para os vereadores da situação, pois assim perdem o diferencial que os distingue de seus oponentes partidários: o acesso ao Executivo, o atendimento da indicação ou equivalente. Na medida em que os vereadores migram para a base de apoio do governo, a utilidade esperada do apoio ao poder Executivo diminui, pois aumenta a competição pelos recursos de que este dispõe para distribuição entre os seus aliados. Um elemento de troca do vereador com o Executivo é o seu apoio. Ainda que o recado contido nessas linhas possa não ter consequências práticas, em função da grande dependência dos mandatários proporcionais com relação ao Executivo, há aqui uma sinalização clara da utilidade esperada na troca. O prefeito não é indiferente a esse tipo de sinalização (D’ÁVILA FILHO, JORGE; ALVES, 2014).

Estudos como os de Barreira (1998), Bezerra (1999), Kuschnir (2000), Palmeira e Heredia (2001), Palmeira (1996) mostram a identificação que é feita em municípios do interior brasileiro $^{6}$, nos dias que correm, entre eleições e política, em que o período eleitoral é concebido como "tempo da política". Para esses autores, trata-se de período que, para além dos resultados eleitorais, é decisivo no realinhamento social dessas populações. Em uma situação em que mais do que os partidos pesam as facções; e em que o voto não é, via de regra, uma escolha individual, mas um empreendimento familiar de "localização social", as eleições são o pretexto para a redefinição e reafirmação de pertencimentos e a definição de fidelidades. Se isso é verdadeiro para toda e qualquer eleição, pois toda e qualquer eleição, ao mesmo tempo em que envolve disputa é concebida como festa, vale especialmente para as eleições municipais, que representam uma espécie de matriz para as demais.

As eleições para cargos estaduais e federais tendem a funcionar nos municípios pequenos e médios - apesar de Palmeira (1996) afirmar que funciona mais o tamanho do que o ser rural ou urbano, ainda que haja capitais onde há disputas entre poucas famílias pelos principais postos políticos - como uma forma de referendo das divisões sociais e da distribuição de poder operada pelas eleições municipais. As campanhas políticas não se resumem a uma disputa de cargos eletivos. Possuem, ao contrário, significados que lhes antecedem e transcendem os resultados eleitorais. Além da definição de jogos de interesses, alianças e conflitos que se apresentam nesse momento, as campanhas podem ser percebidas através de um dos sentidos dos rituais políticos, que é a expressão de crenças e princípios que justificam e alimentam a própria existência da representação no Estado moderno (BARREIRA, 1998, p.

\footnotetext{
${ }^{6}$ Não somente no interior, mas no contexto geral dos municípios. O termo "tempo da política" traz uma ideia de que a política em si não faz parte do cotidiano dos atores sociais.
} 
29). Além de intermediários políticos, Kuschnir (1999) afirma que muitos vereadores são também "mediadores culturais" entre o mundo dos eleitores, do Poder Executivo e do Legislativo. Atuam como intérpretes desses domínios, participando e estabelecendo vínculos entre seus múltiplos planos de cultura. Logo, os cabos eleitorais aqui estudados também se enquadram nessa afirmação.

Começou-se a falar sobre a campanha eleitoral, em meados de dezembro de 2013, quando Heitor Batista foi chamado para conversar com Julinho Ferreira, candidato à reeleição para Deputado Estadual, sobre uma possível aliança; mas, para isso, Heitor sugeriu que ele deveria ter algumas "garantias", pois sua base eleitoral e sua atuação como vereador na Câmara Municipal em Arapongas estava em evidência. Essas garantias eram: um emprego para um dos filhos em um órgão público e parte do dinheiro da campanha antecipada. Essas duas garantias foram atendidas. Heitor recebeu o valor prometido e seu filho assumiu um cargo na ouvidoria de um órgão público do estado em fevereiro de 2014. Situações como essa são normais, no sentido de que acontece na maioria das vezes, dependendo dos laços políticos que o ator político possuir.

Mesmo com acordos políticos já firmados, da noite para o dia, eles podem ser desfeitos. Para poder explicar o fato, deve-se colocar no contexto da atual campanha em Arapongas. Na última eleição municipal, o grupo Cochara estava com o governo de Marcelo Déda (PT) e o Matamata estava junto com o Democratas. Com a eleição desse ano, as alianças se dissolveram: Julinho Ferreira, do Cochara, se encontrava na campanha para o candidato ao governo Benjamim Azevedo (PMDB), o qual também recebeu apoio do grupo Matamatá e do prefeito do município, Vagner Freire. Já o cabo eleitoral Heitor, que estava com o Julinho Ferreira, fez campanha para o candidato ao governo Daniel Caetano (PSC) com o candidato Carlos de Barros do mesmo partido, com isso, o cabo Heitor se encontrava em uma situação delicada, pois não podia participar dos eventos do seu deputado estadual por ter a presença de Benjamim Azevedo e, assim, comprometia a sua "visibilidade" para com Daniel Caetano. Logo, o cabo optou por desistir do seu deputado estadual e apoiar outro candidato do mesmo "lado" que o seu governador. A "ajuda" que o cabo recebeu de Julinho Ferreira foi devolvida e eles conversaram sobre a situação, de maneira bem tranquila; o cabo alegou que seria difícil acompanhá-lo devido às suas escolhas políticas no momento e que de maneira nenhuma faria campanha contra a ele. Esse fato é interessante porque mostra como alianças políticas se alteram principalmente no âmbito local, em que a política é dividida entre duas facções que dificilmente compartilham apoio e poderes entre si. 
SANTOS, P. S. S. O papel do cabo eleitoral nas disputas pelo poder local: saber profissional, campanha política e facções em Arapongas/SE (2014-2015)

Quando acompanhei a ida de um dos cabos eleitorais para a capital sergipana para uma reunião com uma deputada para atualizações da campanha em Arapongas, fui percebendo que há necessidade de cooptação de outras bases eleitorais (locais ou não) para mostrar a sua relevância e força política. A reunião ocorreu tranquilamente, só que na volta o cabo foi até a casa da cunhada para falar com o esposo dela, um empresário do ramo de varejo em Aracaju, que foi candidato a prefeito de outra cidade do interior do estado na última eleição de 2012, sobre uma possível aliança política com o candidato Daniel Caetano e com o candidato a deputado federal Carlos de Barros, mostrando que essa aliança só traria benefícios para ele, que já teria condições suficientes para poder se eleger prefeito na eleição de 2016, tendo o apoio dos candidatos. Uma semana depois foi firmado o apoio do empresário com os dois candidatos; o cabo eleitoral recebeu uma ligação do próprio Daniel Caetano perguntando como era o trabalho dele, pedindo praticamente recomendações. Nesse caso, vê-se a ligação direta entre o candidato e o cabo eleitoral (líder) devida à importância que o próprio candidato deu ao ligar para o cabo, e esse vê-se a oportunidade de mostrar a relevância da sua palavra:

\footnotetext{
Não, Dr. Ele é muito competente, é meu concunhado. Homem sério, tem uma base muito forte em Maruim; disse a ele que ele tinha que ficar com o senhor porque ele iria comandar a cidade, porque com o senhor ele ia ter tudo. Ele foi candidato a prefeito lá, e tendo o prefeito do outro lado, fica mais fácil para o senhor conseguir os votos dele. (Entrevista - SANTOS, 2016)
}

Outra situação foi a cooptação de outros cabos eleitorais que se candidataram a vereador na eleição de 2012 em Arapongas e que não se elegeram. Buscar apoio de outros cabos que têm suas próprias bases eleitorais é uma estratégia bem praticada entre as lideranças políticas para fortalecer as suas bases. Obviamente, eles simplesmente não optam por apoiar qualquer um. As ditas "conversas" ou "reuniões" entre os cabos e os candidatos são o momento em que são ofertadas "ajudas", como oportunidades de oferecer empregos para os "amigos". Isso foi observado em três reuniões com dois deputados estudais e um deputado federal. Nas três primeiras reuniões, os cabos diziam as suas condições: "preciso de alguns empregos para eu poder dar aos meus amigos e mostrar minha força, sabe?", "eu tenho muitos contatos e isso pode fortalecer muito a nossa base em Arapongas, mas para isso a gente precisa acertar uma ajuda pra eu poder fazer meus trabalhos", "o meu bairro é o maior da cidade e toda a minha base se concentra nele, meus votos são garantidos, mas pra efetivado, eu tenho que trabalhar para além do meu bairro e é necessária uma ajuda boa pra isso". Em nenhum momento eles falam os termos "quantia", "dinheiro", "valor" ou algo parecido, por ser algo indelicado, e só se chega ao assunto diretamente apenas no final da conversa. 
Com a campanha eleitoral já estando em vigor, esse quadro foi mudando aos poucos. Uma das reuniões com o coordenador da campanha para a candidata ao Senado Luciana Almeida, os valores já apareceram e os pedidos aumentaram. Primeiramente, todos os cabos eleitorais que estavam presentes (nove ao todo) entraram juntos para uma reunião geral sobre o andamento da campanha, o que deveria ser feito. Posteriormente, uma reunião individual foi feita com cada cabo eleitoral, na qual se definiriam alguns valores para a campanha. Nesse momento, só pude acompanhar um cabo eleitoral, pois os outros disseram que não se sentiriam à vontade tendo uma pessoa "de fora" em um momento delicado como esse. No que pude estar presente, valores bem consideráveis seriam o suficiente para fazer uma campanha decente, pois, segundo o próprio cabo, o dinheiro seria basicamente para gasolina, pagar os seus cabos eleitorais secundários e dar uma ajuda aos que ele achasse que precisassem. Assim ficou o acordo para a campanha. Todavia, ele fez um pedido pessoal, que como a sua família também estaria trabalhando na campanha, e seus filhos ainda não tinham nenhuma outra renda, seria de grande ajuda se fosse possível arranjar um trabalho na prefeitura para um de seus filhos. $\mathrm{O}$ coordenador da campanha disse que arranjaria o emprego, mas que não seria de imediato, pois teria que ver em qual setor seria possível e se haveria alguém com o contrato para vencer.

A importância das relações pessoais no âmbito do exercício da representação política parece estar associada, entre outros aspectos, a uma concepção sobre a política que a articula à distribuição de favores e ao peso relativo que têm instituições políticas, como os partidos, na competição por um mandato, e principalmente dentro das facções políticas. No caso do Brasil, Bezerra (2013) exemplifica casos de relações pessoais, a questão da reputação e a representação política; para além do Brasil, Whyte (2005) também fala sobre esses temas, mostrando, assim, que essas atitudes não são uma prerrogativa brasileira, muito menos que não é uma questão de corrupção, mas, sim, papel intrínseco da dinâmica política. A presença na política de relações pessoais fundadas na circulação de bens e serviços tem sido observada especialmente durante a campanha eleitoral, como já mencionamos anteriormente. As contribuições analíticas mais promissoras do ponto de vista do entendimento do lugar que essas relações ocupam nas práticas políticas se encontram em trabalhos que se recusam a pensá-las estritamente em termos de clientelismo político, corrupção eleitoral ou como o resultado de ausências (de consciência, ideologia ou programa partidário).

No outro dia, houve sessão na Câmara dos Vereadores. Antes do início, os cabos eleitorais Heitor Batista e Diego Fontes falaram a sós sobre a reunião com coordenador de campanha citado mais acima em que alguns pediram valores exorbitantes para fazer a campanha; segundo eles, isso não poderia acontecer, pois acaba passando um descrédito do 
SANTOS, P. S. S. O papel do cabo eleitoral nas disputas pelo poder local: saber profissional, campanha política e facções em Arapongas/SE (2014-2015)

trabalho deles, uma imagem de mercenários. Além desse acordo com o coordenador de campanha de Luciana Almeida, o cabo eleitoral Heitor também fez acordo com Carlos de Barros e com o candidato a deputado estadual Fernando Gomes (que substituiu Julinho Ferreira). Além de receber "ajuda" para realizar a campanha, também foi pedido emprego para os seus outros filhos. Um apoio por um filho empregado, necessariamente. Aos que foram pedidos os empregos, exigiam que os empregos dados não fossem uma mera mesada, e que os empregados deveriam estar trabalhando. Já com o deputado federal Carlos de Barros, foi uma "ajuda" até então temporária.

Pode-se fazer um paralelo entre esses candidatos e os próprios cabos eleitorais. Os cabos pedem emprego aos candidatos (mesmo que não sejam para si), ao passo que a população sempre está à procura desse tipo de cabo eleitoral para lhe conseguirem emprego; entregamlhes currículos e os cabos sempre falam "Eu vou ver o que posso fazer, porque eu mesmo não tenho como lhe dar um emprego. Não tenho empresa nem comércio" (SANTOS, 2016). Esse caso remete a uma situação em que o cabo Eleitoral Heitor passou em 2010, quando era cabo eleitoral de outro candidato a deputado federal e estava também tentando a reeleição em 2014 sendo relatava pelo cabo eleitoral. Heitor realizou um almoço em sua residência e convidou os seus principais cabos secundários para apresentar o candidato e, assim, colocar em pauta todas as demandas que o Heitor e a sua base colocariam para ele. Primeiramente foi feita uma conversa aberta, o candidato apresentou as suas propostas para o mandato e como o município sairia ganhando com ele na câmara de deputados. Logo após, foi servido o almoço - evento esse que sempre se encontra presente no cotidiano da política como mostra os trabalhos organizados por Palmeira e Barreira (2004) - onde todos continuaram conversando e, em seguida, começaram as conversas individuais. Enquanto todos estavam na área externa da casa almoçando, as conversas individuais aconteceram na segunda sala da casa: o candidato e um cabo eleitoral secundário, ambos sentados no sofá, colocam as suas propostas e contrapropostas. Para além dessa situação, outro espaço da casa que também estava inserido nesses bastidores era a cozinha. A esposa de Heitor foi a responsável pelo almoço e as pessoas que constituíam a base eleitoral iam até o cômodo parabenizá-la pelo seu trabalho.

O importante de citar isso é mostrar que a política não é só feita pelo cabo eleitoral, mas, às vezes, a sua própria família adentra nessa política de bastidores. Enquanto a esposa do cabo realizava o almoço, os filhos eram responsáveis por proporcionar um ambiente caseiro à situação, conversando com a equipe de apoio do candidato e ajudando a servir quando fosse necessário. O resultado disso foi a fala do candidato quando a reunião foi encerrada e só restava Heitor, sua família, algumas pessoas próximas do cabo, o candidato e sua equipe. O candidato 
colocou que a presença da família e a participação da mesma demonstrava que política não se faz sozinho e que quando feita com familiares, ela não dá espaço para coisas desconstrutivas. A partir daí visitas constantes do candidato foram feitas à família devido à criação de laço. Mesmo que não se trate de uma família tipicamente política, com vários integrantes ocupando cargos eletivos ou que já fizeram carreira na política, a participação da família no que concerne ao trabalho de cabo eleitoral é importante. Os próprios filhos acompanhavam o cabo em suas visitas em todos os momentos da campanha e assim aconteceu na eleição de 2014, sendo essa uma das formas da introdução à política, através da herança (CANEDO, 2004).

\section{OS TRAÇOS DA CAMPANHA ELEITORAL E O SEU DESENVOLVIMENTO}

Antes da campanha eleitoral, estava acompanhando o cabo eleitoral Paulo Guerra em um dia de terça-feira para fazer visitas a alguns conhecidos para traçarem estratégias para a campanha eleitoral, e no carro estávamos ouvindo um programa da rádio Nova Aliança FM, no qual o radialista dizia que "os políticos de Arapongas devem se lembrar de suas obrigações. Estão ganhando para isso. Só pensam em campanha eleitoral. Só pensem quando tiver perto, e não durante o ano todo". Perguntei ao cabo quando ele começava a pensar nas campanhas eleitorais e obtive a seguinte resposta:

\footnotetext{
Eu penso em campanha eleitoral, seja ela municipal ou estadual, quando eu faço o meu trabalho como político. Se eu faço o meu trabalho bem, necessariamente eu estou apto a me candidatar. Claro que a gente sempre pensa na próxima campanha. A gente vive disso, não tem como fugir se é o nosso dia a dia. (Entrevista - SANTOS, 2016)
}

Como proposta, o acompanhamento do "cotidiano da política" é importante para conhecer como que é o dia a dia de um político profissional. Com a volta das sessões na Câmara Municipal, é primordial o acompanhamento das atividades da casa. As sessões têm início às nove horas da manhã, às segundas e quartas. Na primeira sessão do semestre, acompanhei um vereador até a Câmara, no horário de oito horas, onde ele me apresentou aos funcionários da casa, como pesquisadora, dizendo que iria acompanhar o cotidiano dos vereadores, entre outras coisas. Tdavia, o vereador não ficou na Câmara: andou pelo centro da cidade, falou com populares, distribuiu santinhos, como também teve a oportunidade de ser abordado por outros cabos eleitorais (foram quatro ao total, que não exercem na política profissional) de outros candidatos. Nesse momento, fez-se uma rodinha e começaram a debater sobre as carreatas que aconteceriam durante a semana e sobre as suas campanhas; durante a fala deles surgiu o termo "cabo eleitoral secundário"; todos os quatro usaram esse termo para se referirem aos seus 
SANTOS, P. S. S. O papel do cabo eleitoral nas disputas pelo poder local: saber profissional, campanha política e facções em Arapongas/SE (2014-2015)

próprios cabos, à sua base eleitoral. Quando perguntei o que viria a ser o "cabo eleitoral secundário" tive a resposta de que "são os que [es]tão rodando os povoados todos a meu mando" (SANTOS, 2016). Fato interessante que mostra a relação dessas lideranças com as suas bases eleitorais e como eles são tratados.

Na Câmara, a tribuna é utilizada para os vereadores terem o seu momento de denunciar condições em que ruas, bairros, povoados se encontram; de parabenizar o serviço de alguma secretaria; de falar o que lhe bem entender. Com o início da campanha eleitoral, a tribuna também tem servido como espaço para fazer campanha. Um dos vereadores falou sobre o andamento da reforma da praça principal do povoado Aldeia Grande, que é de responsabilidade do governo do estado, iniciada no mandato do ex-governador Marcelo Déda, que se encontrava parada há meses, e quando foram retomadas as atividades, parou de novo devido às intensas chuvas; o mesmo caso é o do Balneário "Bica", na saída da cidade de Arapongas, reforma também de responsabilidade do governo do estado. Segundo o vereador, isso é algo que compromete a visão de responsabilidade que o governo tem, e que isso não pode ser deixado passar, e que "se Deus quiser o outro [Daniel Caetano] assume em 2015 e o estado vai pra frente" (Entrevista - SANTOS, 2016). Apesar de ele não ter usado diretamente o nome do candidato, todos têm conhecimento que ele se encontra apoiando Daniel Caetano. Outros vereadores também usaram a tribuna para falar sobre seus candidatos, mas dessa vez de forma explícita. Um usou o espaço para falar sobre o candidato Julinho Ferreira: "ele é a escolha certa para ser um bom representante, ele é um menino direito, jovem, inteligente, e ele com certeza merece ganhar. O seu número é muito fácil de decorar, xxxxx" (Entrevista - SANTOS, 2016). Mesmo sendo uma forma totalmente explícita de incitar o voto, em momento algum o vereador foi repreendido pelo presidente da Câmara.

A continuidade observada entre as relações políticas e os laços cotidianos permite relativizar a ideia de pensar a atividade política como constituída de relações sociais de natureza específica e estranhas ao dia a dia das pessoas. A concessão de bens e serviços sob a forma de favor tem sido uma estratégia conscientemente utilizada por representantes políticos com o objetivo de acumular um capital de relações pessoais a partir do estabelecimento de dívidas pessoais, fazendo parte do "caminho das pedras" que Bezerra (2004) explora. Para fazer uma campanha eleitoral, o cabo eleitoral utiliza-se de todas as opções que o cercam. Durante a inauguração do comitê de Daniel Caetano na capital, acompanhei o CE Heitor, que pediu para que eu colocasse o adesivo do candidato, alegando que seria mais fácil eu me agregar aos presentes e para verem que tinha gente acompanhando ele. Quando ele se aproximava de algum conhecido, eu era apresentada como "a pesquisadora que está fazendo um trabalho sobre o dia 
a dia do cabo eleitoral" (SANTOS, 2016), falando que era necessário um trabalho como esse para que todos soubessem como é "árdua" a campanha de rua. Nesse momento, o cabo eleitoral fez uma espécie de desabafo:

\footnotetext{
É um pede-pede que não acaba mais. A gente tenta fazer um trabalho honesto, sem compra de voto e essas nojeiras que muitos fazem, manchando nosso trabalho. Se a gente der, depois vem reclamar que político é corrupto. Também não é assim, não é? Tem muita gente que não entende o nosso lado. Acham que a gente tem tudo na mão. Mas quem sou eu? Todo dia eu trago gente pra Aracaju pra o hospital, no meu carro, com minha gasolina. É sacrifício o que a gente faz. (Entrevista - SANTOS, 2016)
}

Comentários assim eram constantes; quando se tratava do trabalho que esses cabos faziam e o reconhecimento que lhes era dado, os cabos falavam abertamente com expressão de tristeza, em alguns momentos, de revolta. Quando questionados do motivo que continuavam trabalhando na política, a resposta era unânime: "A política é o que eu tenho que fazer. Nasci pra isso" (Entrevista - SANTOS, 2016).

\section{CARACTERIZAÇÃO DAS FACÇÕES E SEUS NOVOS E VELHOS INTEGRANTES: O QUE ISSO IMPLICA NA ATUAÇÃO DO CABO ELEITORAL?}

A facção que assume o controle de um município - sintomaticamente identificada pelas demais como "situação" - é, de modo quase automático, associada à política institucional, à política "externa" e legítima, ao governo (entidade que corporifica o poder externo), e as demais postas na posição residual de "oposição". Sua pretensão não é propriamente representar a comunidade, mas ser reconhecida pelos de fora e projetar-se para dentro como se fosse toda a comunidade (PALMEIRA, 2004). Para essa parte do capítulo, optei por deixar os nomes dos candidatos para ser mais bem visualizada as relações e laços "sem querer" entre as facções em Arapongas.

Tendo já sido consolidadas as alianças, as facções políticas em Arapongas ficaram com aspectos diferentes das eleições estaduais de 2010, como também da municipal em 2012. Apesar de não ter como explicitar como as dinâmicas faccionais foram sendo modificadas com o tempo, tanto a integração de novos atores políticos, como também a elevação das figuras dos chefes políticos foram importantes para a consagração dos grupos políticos em Arapongas. As famílias políticas Vieira e Ferreira tiveram os seus nomes representados nas eleições de 2014 com a candidata à reeleição, a deputada estadual Mara Vieira (DEM); o candidato à reeleição, 
SANTOS, P. S. S. O papel do cabo eleitoral nas disputas pelo poder local: saber profissional, campanha política e facções em Arapongas/SE (2014-2015)

o deputado federal Marcel Vieira (PMDB), e o candidato à reeleição a deputado estadual Julinho Ferreira (PSD).

Nas eleições de 2014, o grupo Matamatá optou por apoiar o candidato ao governo Benjamim Azevedo (PMDB), que tinha o apoio do PT, partido que apoiou o ex-prefeito de Arapongas nas eleições de 2012; e Jonatas Oliveira (PSC), que também se candidatou a deputado estadual, todavia, em 2014, apoiou Daniel Caetano (PSC) ao governo. Daniel Caetano teve o apoio de um grande político da capital sergipana e esposo da candidata ao senado Luciana Almeida, sendo que esta última recebia o apoio de Mara Vieira. Esta, por sua vez, não declarava nos comícios nem em seu material de campanha qual governador estaria apoiando. Julinho Ferreira tinha o apoio de sua família, que também fazia campanha para o candidato do PT ao senado Ricardo Lemos.

Interessante observar que com essas alianças, fica perceptível como a configuração dos grupos políticos mudou efetivamente, pois, necessariamente, quem faz parte do grupo Matamatá apoiaria os candidatos do seu grupo, mesma coisa com os do Cochara. Todavia, na prática, os apoios não levaram tanto em consideração o "ser cochara" e "ser matamatá". Antes da sessão de 7 de agosto de 2014, alguns vereadores se reuniram aguardando o início da sessão e aproveitam para falar sobre a campanha. Um deles falou que o próprio prefeito disse diretamente a ele com as seguintes palavras: "esse é o momento de vocês conseguirem algo porque grupo nenhum elege vereador. Devem procurar apoio mesmo, de quem quiser" (SANTOS, 2016). Mesmo com a maioria sendo da situação, até esse momento eram dez vereadores apoiando Daniel Caetano. O atual prefeito de Arapongas, Vagner Freire, e seu grupo apoiaram Benjamim Azevedo ao governo.

Interessa, por exemplo, a um candidato a deputado estadual ou federal que, não tendo bases eleitorais, isto é, nem eleitores nem cabos eleitorais distribuídos ao longo de todo o estado, associar seu nome, em municípios onde é desconhecido ou menos conhecido, a diversos vereadores que tenham peso e base eleitoral e que, atuando como verdadeiros cabos eleitorais, garantam sua entrada nesses lugares. Mas interessa também ao candidato "local". Assim, por exemplo, estar associado a um determinado deputado, ou candidato a deputado, que tenha peso dentro da facção já é em si importante para um vereador, e ainda o será mais se esse político tiver sua base eleitoral no mesmo território em que o candidato concorre. Como esses grupos já se mantêm há certo tempo, a rede política dos mesmos dificilmente mudará, pois já acarreta no status do ator estar vinculado a tal grupo/chefe político, como fala Kuschnir (2000, p. 56) que "o partido é identificado com seus comandantes e seus amigos. Tanto que os partidos e 
candidatos costumam ser referidos a partir do nome de um 'chefe político'. À pergunta 'fulano é de quem?', responde-se: 'É do partido do sicrano"”

Há uma correspondência com o que acontece pelo lado dos militantes. Eles sempre dizem trabalhar para alguém, isto é, para um candidato em particular, e nunca para o partido em geral ou para vários candidatos que estão disputando os mesmos cargos. Dentro da facção, ao contrário, a disputa pelo espaço é uma disputa constante. Isso indica a existência de uma temporalidade específica para os políticos, isto é, para aqueles que fazem política o tempo todo, que se diferencia da temporalidade concebida pelas populações como "tempo da política" (BARREIRA, 1998). O que aparece como sendo uma disputa entre facções é aquela que acontece durante a campanha eleitoral, pois a política, fora do período eleitoral, faz-se fundamentalmente dentro da própria facção. E retomando a fala do CE Paulo Guerra, são eles que levam o nome dos grupos e que os fazem continuar no dia a dia da população, pois ela também exige saber de qual "lado" eles estão, tanto nas eleições como depois.

Mas e aqueles que não assumem diretamente que fazem parte de um grupo político? É o caso do CE Noé Francisco, que falou em uma das sessões na Câmara que não é nem do Matamatá e nem Cochara, complementando com "meu compromisso é com o povo". Afirmou que foi eleito pela ala do Matamatá, entretanto, isso não diz nada. Segundo ele, sentiu-se obrigado a participar de um grupo para poder se eleger, porque "infelizmente a política de Arapongas ainda é assim".

\footnotetext{
Não vou ficar sendo mandado por chefe político nenhum. Tenho que fazer a minha própria política para o povo. Essa política de grupo em Arapongas tem que acabar. Só traz atraso pra população. A gente que está mais perto do povo sabe das dificuldades que o povo passa. Ao invés que ficar discutindo sobre apoio de cochara e matamatá, a gente tem que focar no que é melhor pra Arapongas, e o que for melhor eu vou estar junto (CE Noé Francisco) (Entrevista - SANTOS, 2016).
}

Como forma de rebater, o CE Paulo Guerra, apesar de apoiar a situação, no caso os candidatos Mara Vieira e Benjamim Azevedo, afirma que são visíveis as falhas do governo, mas que sabe que esses candidatos são capazes de melhorar o estado e levar mais recursos para Arapongas.

Ao contrário da simples confirmação do mando de um determinado chefe político ou facção sobre uma mesma clientela, as eleições são a ocasião, por excelência, para as migrações entre facções. O "tempo da política" é o tempo em que são possíveis os rearranjos ou em que são formalizados os rearranjos de compromissos que foram se dando entre duas eleições, que, de outra forma continuariam sendo lidos como ingratidões ou traições. Mesmo quando o resultado é a confirmação do mando da mesma facção, esses movimentos são fundamentais. 
SANTOS, P. S. S. O papel do cabo eleitoral nas disputas pelo poder local: saber profissional, campanha política e facções em Arapongas/SE (2014-2015)

Entre duas eleições muita coisa se passa: conflitos interpessoais inviabilizam a permanência de duas pessoas na mesma facção; favores de diferentes fontes criam para um mesmo indivíduo ou para uma mesma família problemas de lealdade e assim por diante. O tempo da política é que vai permitir mudanças de fronteira capazes de readequar a sociedade à imagem que ela se faz dela própria (PALMEIRA; HEREDIA, 2001).

O comitê da candidata à reeleição, a deputada estadual Mara Vieira, se encontrava na Praça do Forródromo, local estratégico, no centro da cidade. As cores predominantes são o azul e amarelo. Apesar de as cores usadas em seu material de campanha serem azul, branco e vermelho, o amarelo estava presente, cor que há várias eleições representa o Matamatá nas eleições municipais. Os adesivos e cartazes expostos no prédio do comitê são somente da candidata e de Luciana Almeida; há também um cartaz com a foto de Jonas Vieira, pai da candidata, chefe do Matamatá.

$\mathrm{Na}$ inauguração do comitê da candidata à reeleição e deputada estadual Mara Vieira, uma "confusão" de apoios se caracterizou de uma forma que até então não tinha acontecido nas campanhas em Arapongas, seja em nível municipal ou estadual. Sendo a candidata do Matamatá, necessariamente as lideranças do grupo a estariam apoiando. No trio elétrico, no momento dos discursos, o locutor sempre falava nomes de candidatos e os seus respectivos números: Mara Vieira, 25983; Marcel Vieira, 1599; Luciana Almeida, 258; Benjamim Azevedo, 15; e Aécio Neves, 45. Quando Luciana Almeida estava presente, porém, o locutor só falava o seu número e o de Mara. Havia a distribuição de adesivos de Mara e Marcel Vieira, Luciana Almeida e Aécio Neves. Mara só usava os adesivos dela, de seu sobrinho e de Luciana Almeida. E as bandeiras eram somente da própria Mara e de Marcel Vieira. Apesar de ele não estar presente fisicamente, a sua imagem era sempre lembrada.

Com essa chapa, percebe-se a confusão entre os apoios e mistura de coligações adversárias. Mara Vieira, Luciana Almeida e Aécio Neves pertenciam a uma coligação, e Marcel Vieira e Benjamim Azevedo pertenciam à outra. Mara Vieira, do DEM, foi secretária da Saúde da capital, onde o esposo de Luciana Almeida era prefeito e assim já vinham se aliando desde eleições anteriores, nas quais o partido de Luciana Almeida, o DEM, aliou-se ao PSDB, partido de Aécio Neves, e do prefeito de Arapongas, Vagner Freire. Mas Marcel Vieira, sendo o principal candidato a deputado federal do Matamatá, pertence ao mesmo partido que Benjamim Vieira, adversário de Daniel Caetano, do PSC, que tinha como candidato à presidência Aécio Neves, e aliado a Luciana Almeida. O prefeito Vagner pediu voto para Mara Vieira, utilizando do discurso familiar, dizendo que Jonas Vieira é um grande homem, de bom coração, que nunca mediu esforços para ajudar a quem precisasse. Pediu voto pra Aécio Neves, 
dizendo que Dilma e Lula, junto com o PT, acabaram com o Brasil. Todavia, Marcel Vieira estava com Benjamim, que tem apoio de Dilma e é coligado com o PT. Também pediu voto para Benjamim, justificando que o mesmo ajudou com o asfalto em Arapongas, porém, não pediu voto para Luciana Almeida.

Esse mosaico de apoios complica a atuação dos cabos eleitorais. A maior parte dos cabos eleitorais que estavam presentes não apoiava pelo menos um dos candidatos do Matamatá. O cabo eleitoral João Pedro não apoiava Benjamim Azevedo, mas Daniel Caetano. O cabo eleitoral Artur Machado não apoiava Mara Vieira e nem Luciana Almeida, mas Julinho Ferreira e Ricardo Lemos.

Gráfico 1 - Relação entre os cabos eleitorais e os candidatos

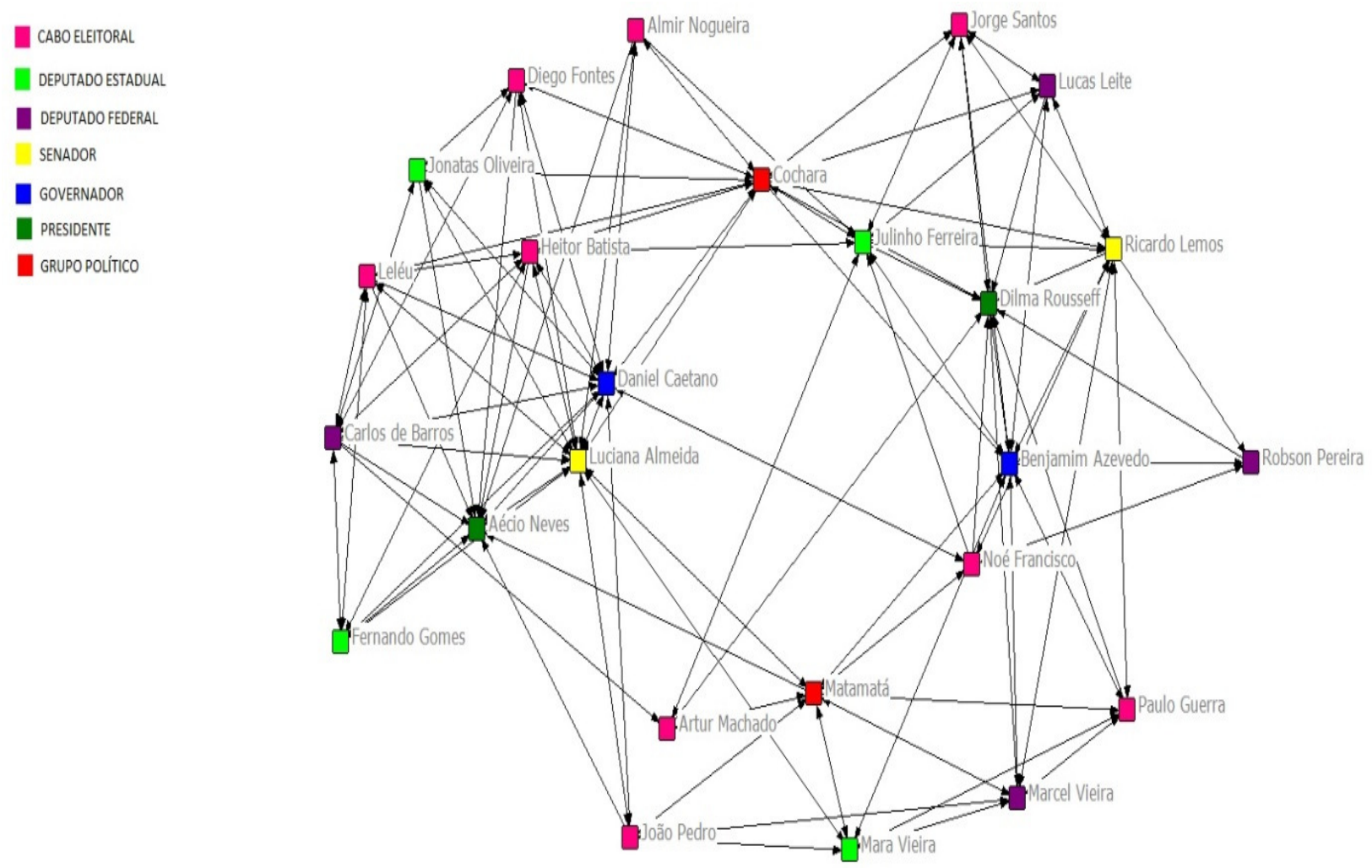

Fonte: Elaboração própria.

Palmeira e Heredia (2001, p. 131) demonstram que

a circunscrição da política como atividade legítima de todos a um período determinado inibe as atividades políticas de grupo no cotidiano. A militância permanente - marca do trabalho político dos partidos de esquerda e, no passado, também de certa direita - e até mesmo a presença muito constante do político nas comunidades é vista com desconfiança. A política é identificada com divisão (ao contrário da família, que simboliza a unidade) e, por isso, a atividade política constante é vista como uma ameaça à comunidade. Sem 
SANTOS, P. S. S. O papel do cabo eleitoral nas disputas pelo poder local: saber profissional, campanha política e facções em Arapongas/SE (2014-2015)

dúvida, aquele padrão de militância pode legitimar-se ao longo do tempo, mas trata-se de um processo difícil e de resultados incertos.

Esse caso se diferencia do caso em Arapongas, nos quais os políticos são chamados pela comunidade para participarem de suas ações, tanto com ajuda como também para dar credibilidade ao bairro, povoado etc. Não quer dizer que Arapongas seja uma cidade "politizada", mas de que a política faz parte do cotidiano da cidade, não somente no "tempo da política". Os cabos eleitorais, para fazerem uma boa campanha, precisam ter um território para atuar em que já sejam conhecidos pelos seus trabalhos e que tenham quem trabalhe com eles nesses locais. Caso já tenha feito alguma festa em alguma data comemorativa, por exemplo, no dia das crianças, ou se ajudou a levar um posto de Saúde para a comunidade, isso fará com que a sua atuação tenha mais crédito no local do que outro cabo eleitoral que não tenha "feito" algo para a comunidade. E sempre com o cabo eleitoral, será levado o nome da facção a qual faz parte, uma forma indireta de fazer presente a facção, mesmo que o grupo não tenha ajudado.

Se, por um lado, o eleitor considera como obrigação que o vereador atenda a suas demandas, por outro essa concepção está incorporada à representação que o vereador tem de sua própria atividade política. A obrigação de atender é dada por motivações distintas, desde a gratidão por ajuda recebida (em campanhas, por exemplo) até por "questões humanitárias". O atendimento, no entanto, possui regras implícitas, explicitadas apenas para os membros do grupo que acompanha o vereador. Entre as principais estão aquelas presentes em toda economia da dádiva: o atendimento, o favor e a ajuda são sempre concessões aparentemente generosas, desinteressadas. Assim, mesmo que a motivação para atender responda a critérios diversos, não há dúvida de que a dinâmica da relação entre eleitor e vereador, assim como de grande parte da administração pública, está inserida no circuito da dádiva e em sua lógica específica. A dádiva é o operador que vincula e obriga, estabelece e renova alianças. Ela é constitutiva das relações políticas no município. Sobre isso, Kuschnir (2000) em seu trabalho relatou o caso dos Silveira e a necessidade deles em atender a demanda do bairro que representavam e tinham como base eleitoral. Passa a ser elemento constitutivo do cotidiano da política municipal e que muitas vezes perpassa os cargos eletivos, vide o trabalho de Bezerra (1999).

Os vereadores estão inseridos em um circuito de trocas que, mesmo a contragosto, impele-os a atuar da maneira como atuam, atendendo às demandas. A clara percepção que todos têm da falta de expressão eleitoral que a recusa ao assistencialismo traria obriga-os a atuar no mesmo sentido. A dinâmica da competição interna é implacável, pelo menos para os que pretendem a reeleição. A distinção feita por Kuschnir (1993, p. 43) entre políticos "ideológicos" e políticos "assistencialistas", na Câmara de Vereadores do Rio de Janeiro, não se aplica ao 
município de Arapongas. Não há espaço para políticos orientados em termos ideológicos, se por isso entendemos um comportamento orientado por linhas estabelecidas nos programas dos partidos políticos. Fora do assistencialismo não há salvação.

Kuschnir (1993; 1999), de modo similar, mostrou que os vereadores da cidade do Rio de Janeiro dependem do Executivo para materializar o atendimento aos seus eleitores. A falta de capacidade do Legislativo de fiscalizar o Executivo expressava-se, entre outros aspectos, na dependência dos vereadores em relação à capacidade de atendimento às suas demandas, feitas pelos eleitores - no que dependem do Executivo. Se, ao desempenhar o papel de broker, o vereador "garante uma ascendência sobre a população, em relação ao Executivo ocorre exatamente o contrário" e, portanto, "manter e alimentar a relação com o Poder Executivo é o que garante ao seu papel de vereador o prestígio, junto aos eleitores, de agente da mediação" (KUSCHNIR, 1993, p. 116).

\section{CONCLUSÕES}

Por mais que essas vertentes das Ciências Sociais busquem estudar a representatividade política no âmbito local, raramente mencionam o papel do cabo eleitoral em seus estudos, principalmente os que se pretendem a estudar as relações entre deputados e senadores com as suas bases eleitorais. Buscamos dar mais espaço a esse ator político esquecido ao examinar o cotidiano da política partindo do município. Se a política se inicia no município, por que não dar ênfase aos atores que dela fazem parte? E ainda mais quando propomos o estudo com um objeto que é esquecido por duas vezes: o cabo eleitoral que é vereador.

Mas por que não estudar somente o cabo eleitoral? Devido às especificidades que cercam esse ofício, o cabo eleitoral se divide em dois: o cabo eleitoral dito "principal", aquele que irá trabalhar diretamente com o candidato e que possui um nível de liderança política alto, pelo menos em nível local, como é o caso do vereador; e o cabo eleitoral secundário, aquele que é cooptado ou que já faz parte da base eleitoral do cabo "principal”; essa divisão já é nativa, a qual foi percebida através das observações participantes. Para compreender o ofício de cabo eleitoral escolhemos um município que tem por característica principal a sua divisão entre dois grupos políticos: Cochara e Matamatá.

Nessa estrutura política de dois grupos, que mesmo sendo uma eleição para deputados, senador e governo, o papel dos grupos é importante para o desempenho dos cabos eleitorais. Primeiramente, por eles já exercerem um mandato eletivo em nível local, espera-se que eles apoiem os candidatos dos seus respectivos grupos, mas não é uma regra e, sim, uma opção. 
SANTOS, P. S. S. O papel do cabo eleitoral nas disputas pelo poder local: saber profissional, campanha política e facções em Arapongas/SE (2014-2015)

Apesar da identidade política que essas facções enraizaram no município, os cabos eleitorais são livres para apoiar a quem eles quiserem, pois é nesse momento que eles cravarão um importante passo que é o da sua futura campanha. Um cabo eleitoral que já detém um mandato não irá apoiar alguém só por apoiar ou muito menos ficar de fora da campanha eleitoral, mas irá apoiar aquele que acha que pode lhe dar um retorno futuro. Até porque, nesse momento, os cabos eleitorais irão antecipar a sua própria campanha, uma vez que ele estará voltando às regiões do município em que ele é mais bem recebido e que contêm, assim, a sua própria base eleitoral.

Devido à dinâmica do cotidiano da política, esses cabos eleitorais muitas vezes se encontram forçados a se identificar como pertencente a um grupo ou de outro. Com isso, os partidos passaram a ser confundidos com os grupos políticos, em razão da importância que é dada a eles pela população e por alguns cabos eleitorais, que assumem que, por mais que a política passe a ser vista como um jogo de futebol (em que há dois times disputando) é necessário seguir seus encaminhamentos. Não importa, portanto, a quais partidos eles estejam filiados, pois a questão da ideologia não se encaixa com a existência de dois grupos divididos entre famílias.

Mesmo aqueles que admitem não seguir grupo político, acabam recebendo indicações de outros grupos sobre como atuar. Para esses, participar dos grupos locais demonstra certo "atraso" político, o que seria algo prejudicial, mas esses grupos nada diferem dos outros que eles seguem - somente por se tratar de um grupo em nível estadual no qual, que de certa maneira, esses grupos locais também se encontram enquadrados. No município os partidos podem não ter tanta importância, mas eles precisam estar alinhados aos partidos dos grupos em nível estadual e, assim, manterem-se no jogo das disputas pelo poder local.

\section{REFERÊNCIAS BIBLIOGRÁFICAS}

BARREIRA, I. 1998. Chuva de Papéis. Rio de Janeiro: Relume-Dumará: Núcleo de Antropologia da Política.

BEZERRA, M. O. 2004 “Caminho das pedras”: representação política e acesso ao governo federal segundo o ponto de vista dos políticos municipais. IN: BARREIRA, C. PALMEIRA, M. Política no Brasil. Rio de Janeiro: Relume Dumará: NUAP.

. 1999. Em nome das "bases": política, favor e dependência pessoal. Rio de Janeiro:

Relume Dumará: Núcleo de Antropologia da Política. 
2013. Representantes políticos, relações pessoais e reputação. In: GRILL, I. G.; SEIDL, E. As Ciências Sociais e os Espaços da Política no Brasil. Rio de Janeiro: FGV.

CAMARGO, Carla. 2012. Partidos e grupos políticos num município do sertão de Pernambuco. São Carlos. Dissertação (Mestrado em Antropologia Social), Universidade Federal de São Carlos.

CANEDO, L. 2004. Heranças e aprendizagens na transmissão da ordem política brasileira. Cadernos CERU. São Paulo. série 2, nº 15, p. 103-129.

CARVAlHO, J. M. 1997. Mandonismo, Coronelismo, Clientelismo: Uma Discussão Conceitual. Dados, vol. 40 n. 2. Rio de Janeiro, p. 229-250.

D’ÁVILA FILHO, P.; LIMA, P.; JORGE, V. 2014. Indicação e intermediação de interesses: uma análise da conexão eleitoral na cidade do Rio de Janeiro, 2001-2004. Revista de Sociologia e Política, Curitiba, v. 22, n. 49, p. 39-60, março 2014.

GRYNSZPAN, M. 1990. Os idiomas da patronagem: um estudo da trajetória de Tenório Cavalcanti. Revista Brasileira de Ciências Sociais, São Paulo, v. 14, p. 73-90.

KUSCHNIR, K. 1993. Política e mediação cultural: um estudo da Câmara Municipal do Rio de Janeiro. Rio de Janeiro. Dissertação (Mestrado em Antropologia Social). Universidade Federal do Rio de Janeiro.

NUAP.

1999. Eleições e Representação no Rio de Janeiro. Rio de Janeiro: Relume-Dumará:

. 2000. O Cotidiano da Política. Rio de Janeiro: Jorge Zahar.

LANDÉ, C. H. 1977. Introduction: the dyadic basis of clientelism. In: SCHMIDT, S.W. et alli. Friends, Followers and Factions. A Reader in political clientelism. Berkeley, University of. California Press.

OLIVA, T. A. 1991. Estruturas de Poder. In: DINIZ et al. Textos para a história de Sergipe. Aracaju: Universidade Federal de Sergipe/BANESE.

PALMEIRA, M.; HEREDIA, B. 2001. Política Ambígua. Rio Janeiro: Relume-Dumará: NUAP.

PALMEIRA, M. 1996. Política, Facções e Voto. In: GOLDMAN, M. PALMEIRA, M. Antropologia, voto e representação política. Rio de Janeiro: Contra Capa Livraria.

2004. Eleição Municipal, Política e Cidadania. IN: BARREIRA, C. PALMEIRA, M.

Política no Brasil. Rio de Janeiro: Relume Dumará: NUAP.

QUEIROZ, Ma. I. P. 1976. O mandonismo local na vida política brasileira e outros ensaios. São Paulo: Editora Alfa-Omega. 
SANTOS, P. S. S. O papel do cabo eleitoral nas disputas pelo poder local: saber profissional, campanha política e facções em Arapongas/SE (2014-2015)

SANTOS. P. S. S. 2016. O ofício de cabo eleitoral: entre campanhas, comícios e o dia a dia da politica. São Cristóvão. Dissertação (Mestrado em Sociologia). Universidade Federal de Sergipe.

WHYTE, W. 2005. Sociedade de Esquina. Rio de Janeiro: Zahar. 